Yayınlayan: Ankara Üniversitesi KASAUM

Adres: Kadın Sorunları Araştırma ve Uygulama Merkezi, Cebeci 06590 Ankara

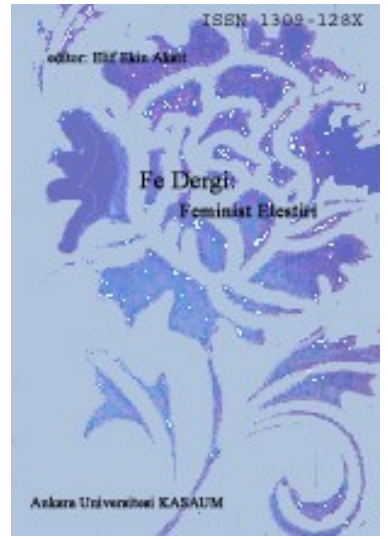

Fe Dergi: Feminist Eleştiri Cilt 5 Sayı 1

Erişim bilgileri, makale sunumu ve ayrıntılar için:

http://cins.ankara.edu.tr/

Bir Savaş Anlatısı Olarak Nefes: Vatan Sağolsun ve Hegemonik Erkekliğin Krizi

Eren Yüksel

Çevrimiçi yayına başlama tarihi: 15 Haziran 2013

Bu makaleyi alıntılamak için: Eren Yüksel, "Bir Savaş Anlatısı Olarak Nefes: Vatan Sağolsun ve Hegemonik Erkekliğin Krizi," Fe Dergi 5, no. 1 (2013), 15-31.

URL: http://cins.ankara.edu.tr/9_3.html

$\mathrm{Bu}$ eser akademik faaliyetlerde ve referans verilerek kullanılabilir. Hiçbir şekilde izin alınmaksızın çoğaltılamaz. 


\section{Bir Savaş Anlatısı Olarak Nefes: Vatan Sağolsun ve Hegemonik Erkekliğin Krizi ${ }^{1}$}

\section{Eren Yüksel*}

2000'li yıllar Türkiye sinemasında narsistik erkek kahramanların toplumsal sorunlara yönelik aşırı şiddet içeren eylemlerine dayanan ve hegemonik erkekliğin yeniden üretildiği milliyetçi propaganda filmlerine ${ }^{2}$ ek olarak milliyetçilik, militarizm ve erkeklik arasındaki iç içe geçen ilişkinin sorgulanmasına yönelik filmler de çekilmiştir. Bu çalışmada bu filmlerden biri olan, erkek karakterlerin çatışmalı içsel süreçlerini sergileyen ve erkeklik krizi bağlamında yorumlanabilecek temsillere yer veren Nefes: Vatan Sağolsun filmine odaklanılmaktadır. Hegemonik erkeklik kodları bakımından tartışmalı temsiller sunan Nefes’in çözümlenmesi aracılığlyla, erkeklik krizinin ne tür imgeler aracılı̆̆ıla sunulduğu ve krize ilişkin bu temsil yapılanmasının hegemonik erkekliğe ilişkin değer, kural ve ayrıcalıkları yeniden üretip üretmediği sorgulanacaktır.

Anahtar Kelimeler: Hegemonik erkeklik, milliyetçilik, militarizm, erkeklik krizi, mazoşizm.

\section{Nefes: Vatan Sağolsun (Breath: Long Live the Homeland) As A War Tale and The Crisis of Hegemonic Masculinity}

During the 2000s in the Turkish cinema, in addition to films telling narsistic male heros' extremely violent acts towards social problems and films in which hegemonic masculinity is reproduced, films questioning the embedded relationship among nationalism, militarism and masculinity have also been shot. This study focuses on Nefes: Vatan Sağolsun, one of the above-mentioned films, which exposes the male characters' conflicting inner processes and allows presentations that can be commented within the concept of masculinity crisis. By means of an analysis of Nefes offering controversial representations in terms of hegemonic masculinity codes, this study aims to question through which images the masculinity crisis is exhibited and whether this representational structure related to the crisis reproduces values, rules and privileges regarding hegemonic masculinity.

Key words: Hegemonic masculinity, nationalism, militarism, masculinity crisis, masochism.

\section{Giriş}

2000’ler Türkiye sinemasını, içerdiği kültürel temsiller bakımından bir yeniden yapılanma dönemi olarak nitelendirmek mümkündür. Birçok toplumsal sorun ele alınmış, farklı kimlikler temsil olanağına kavuşmuştur. Bir tür "kimlikler çoklaşması" olarak tanımlanabilecek bu durum marjinal, dışlanmış grupların kendilerini ifade etmesi için önemli bir potansiyel ortaya koymuştur. Erkek kimliğini de bu bağlamda değerlendirmek mümkündür. Hegemonik erkekliğin ağırlıklı olduğu temsil biçimlerinin yerini, farklı bağlamlar ve ilişkiler temelindeki çoklu erkeklikler almış; erkekliğin performatif inşasına dikkat çeken temsiller yaygınlaşmıştır. Böylelikle 1990 sonrası yaşanan toplumsal dönüşümlerin erkeklik sorunuyla iç içe geçen bir zemin üzerinden irdelenmesi mümkün hale gelmiştir. Çünkü erkeklik hem toplumsal cinsiyet eşitsizlikleri çerçevesinde üretilen temel mekanizmalardan biri hem de sınıf, etnisite, din gibi çelişkiler temelinde şekillenen toplumsal iktidar ilişkilerinin, kendisini hegemonik kılmak için eklemlendiği popüler bir inşadır. Bu bağlamda çalışmanın temel amac1, erkekliğin 2000’ler Türkiye sinemasındaki görünümünü ortaya koymak açısından özgün bir konum üstlenen Nefes filmi aracılığıyla, erkek karakterleri bir kriz içinde sunan temsil yapılanmasının neye karşılık geldiğini ve erkeklik krizinin ne tür imgeler vasıtasıyla sunulduğunu ortaya koymaktır.

\footnotetext{
*Ankara Üniversitesi İletişim Fakültesi, eyuksel@media.ankara.edu.tr
} 


\section{Erkeklik Çalıșmaları Üzerine Kavramsal Bir Arka Plan}

Tarihsel açıdan bakıldığında, erkeklik üzerine eleştirel nitelikli çalışmaların 1960'larda kadın haklarını gündeme getiren feminist hareketin kazanımları üzerine inşa edildiği söylenebilir. Feminist hareketin toplumsal cinsiyet bağlamında kadınlığı sorunsallaştırması, toplumsal cinsiyetle ilişkili olarak erkekliğin de görünür kılınmasını beraberinde getirmiştir. Ayrıca gey hareket de erkekliğin tikelliğini vurgulama yoluyla, normal ve evrensel olarak kabul edilen erkeklik kurgusuna meydan okumuş, erkek ve erkekliği sorgulayan çalışmaların önünü açmıştır. Ancak bu ilk dönemde daha çok bir baskı kaynağı olarak değerlendirilen erkekliğin nasıl işlediğine ilişkin herhangi bir analiz çabasına girişilmediği görülmektedir. ${ }^{3}$ Erkekler ve erkeklik üzerine eleştirel nitelikli çalışmalar zamanla sosyal bilimler, insan bilimleri, biyoloji gibi bilim alanlarının işbirliği içinde gelişmiş ve erkekliğin kökeni, yapısı ve dinamikleri açısından ele alınmasıyla biçimlendirilmiştir. ${ }^{4}$ Bunda postyapısalcılığın gelişimiyle birlikte modern özneye dair mutlak, bütüncül tanımlamaların geçersizleşmesi etkili olmuştur. Tekil, sabit, homojen kimlik tasarımları yerini kamusal alanda dillendirilmeye başlanan, çeşitli özdeşleşmeler ve dışlamalarla sürekli olarak yeniden inşa edilen çoklu kimliklere bırakmıştır. $\mathrm{Bu}$ durumun feminist hareket içindeki yansımaları, bütüncül ve evrensel kadın kimliğinin geçersizleşmesi ve bütün zamanlarda geçerli, tek bir ezilme biçiminin olamayacağına ilişkin kabullerdir. Feminist hareket içinde farklı kadın kimliklerine yönelik ilgi, erkeklik araştırmalarının da yönelimini etkilemiş, tek bir erkeklik yerine tarihsel, toplumsal, kültürel ve sembolik olarak mevcut iktidar ilişkileri bağlamında çeşitli ilişkisellikler temelinde inşa edilen farklı erkekler ve erkeklikler araştırma konusu haline getirilmiştir. Örneğin Michael Kimmel, Jeff Hearn ve R. W. Connell erkekler ve erkekliklerin toplumsal cinsiyetin yanı sıra yaş, sınıf, etnik köken ve ırkçılık gibi farklılıklar tarafından belirlendiğini ve erkeklerin cinsiyetlendirilmesinin, sosyal farklılıklarla kesişimi içinde ele alınması gerektiğini belirtmektedirler. Toplumsal cinsiyet kimliğinin mikro ve makro her ortamda yeniden üretilmesi gereken, "bitmeyen bir süreç" olduğunu ifade eden yazarlar, toplumsal cinsiyet kimliğinin "cinsiyetlendirilmiş etkileşimler birikiminin bir sisteme bağlanması" sonucunda oluştuğunu vurgularlar. Ancak onlara göre bu durum, toplumsal cinsiyet kimliğinin basitçe toplumsal kurumların ve süreçlerin yansıması olduğu anlamına gelmez. Toplumsal cinsiyet kimliği daima hareket halindedir ve bu hareket politik dönüşümlerin gerçekleşebileceği dikişleri sağlamaktadır. $^{5}$

Farklı erkekliklerin araştırılmasında R. W. Connell'in erkekler arasındaki iktidar ilişkilerini açıklayan hegemonik erkeklik kavrayışı belirleyici olmuştur. Toplumsal cinsiyet ilişkilerinin yalnızca kadın ve erkekler arasındaki hâkimiyet-tabiiyet barındıran ilişkiler temelinde anlaşılamayacağını belirten Connell, hegemonik erkekliği, tabileştirilen kadınlar ve öteki erkeklerle ilişkili olarak inşa edilen ve normatif erkek davranışlarının, değerlerinin ve kurallarının denetlenmesine imkân veren değişebilir bir hâkimiyet pratiği olarak değerlendirerek, çoklu erkeklikleri araştırma olanağı sağlamıştır. Bu kapsamda Connell'ın fikirlerini takip eden çeşitli araştırmacılar antropoloji, tarih ve kültürel çalışmalar gibi çeşitli disiplinlerde gerçekleştirdikleri araştırmalarla eleştirel erkeklik çalışmalarının genel çerçevesi olarak ifade edebileceğimiz şu temel bulgulara ulaşmıştır: Herhangi bir yer ya da zamanda, hatta aynı kültür içinde farklı erkeklikler bir arada var olabilir; erkekliğin hegemonik formu kadınlar ve öteki erkekliklerle hiyerarşi içeren ilişki biçimleri aracılığıyla var olur; erkeklikler yalnızca bireysel performanslar aracılığıyla değil aynı zamanda çeşitli kurumlar ya da erkek grupları tarafından da canlandırılabilir; bedensel pratikler erkek kimliğini sabitleme imkânı vermese de, bedene ilişkin hazlar ya da bedenin yaralanabilirliği erkekliğin inşasında etki sağlamaya devam eder; erkeklikler toplumsal cinsiyet etkileşimlerinde aktif bir biçimde üretilir; erkeklerin yaşamları çelişkili arzular ya da pratikler arasındaki gerilimleri cisimleştirir ve son olarak aktif biçimde ve gerilim alanlarında inşa edilen erkekliklerin değişmeleri olasılık dâhilindedir. ${ }^{6}$

Erkeklik çalışmalarında üzerinde durulan bir diğer konu modernleşme sürecinde hegemonik erkekliğin krize girdiği varsayımıyla ilişkili olarak dile getirilmiştir. Çeşitli kuramsal perspektiflerden erkeklik krizini ele alan araştırmacılar hem erkeklik krizinin gerçek olup olmadığı, hem krizin hangi gösterenler aracılığıyla sunulduğu, hem de nasıl anlamlandırılacağı konusunda farklı görüşler ileri sürmüşlerdir. Lynne Segal, Walter Hollstein ve John MacInnes gibi bazı kuramcılar hegemonik erkekliğin feminist hareketin, gey hareketin kazanımları, modernleşme ve küreselleşme sürecinin sonucundaki toplumsal, ekonomik ve teknolojik dönüşümle birlikte bir belirsizlik ve güvensizlik ortamıyla yüz yüze geldiği ve eskisi gibi hegemonik erkekliği üretme olanaklarından yoksun olduğu koşullarda bir kriz içine girdiği saptamasında bulunmuşlardır. Örneğin MacInnes erkeklik krizinin nedeninin modernitenin cinsel farklılık nosyonunu geçersiz hale getirmesi olduğunu ifade ederek, çalışma yaşamının kadınsılaşmasıyla, liberal politik felsefenin ilham verdiği cinsiyet eşitliği yasalarıyla 
ve breadwinner (para kazanma) ideolojisinin ölümüyle birlikte modern toplumda erkek olmanın değerinin düşürüldüğünü belirtmiştir. ${ }^{7}$

Erkeklik krizi saptamasının karşısında yer alanlar ise krizin belirli erkeklik biçimleriyle ilişkili olarak ifade edilebilmekle birlikte genelleştirilemeyeceğini, erkeklerin mevcut koşullara uyum sağlama yoluyla egemenliklerini yeniden tesis edebileceklerini ileri sürmektedir. Erkeklerin içinde bulunduğu durumun krizden çok bir değişimin sonucu olduğunu belirten Connell, erkeklerin kapitalist ilişkiler içinde devlet ve kurumlar dolayımıyla hegemonik konumlarını yeniden inşa edebileceğini savunur. ${ }^{8}$ Benzer biçimde topyekûn erkeklik krizine karşı çıkmasa da mevcut kriz söylemlerinin eksikliklerini ifade eden John Beynon da erkeklik krizinin günümüze özgü olduğu ya da bütün erkekler tarafından aynı şekilde deneyimlendiği görüşlerine itiraz eder. Tekil bir erkekliğe göndermede bulunulamayacağını belirten yazar hem gerçeklikte hem de söylemsel düzeyde farklı erkeklikleri farklı şekillerde etkileyen krizler nosyonundan söz etmenin daha doğru bir yaklaşım olacağının altını çizer. ${ }^{9} \mathrm{Bu}$ noktada hem güncel, somut verileri hem de kuramsal tartışmaları değerlendiren Tim Edwards'ın konuya yönelik kavrayışının krize ilişkin saptama yapmak bakımından yararlı açılımlar sağladığı söylenebilir. Erkeklik krizine yönelik tespitlerin genel olarak içteki ve dıştaki kriz olmak üzere iki başlık altında toplandığını belirten Edwards, içteki krizin erkeklerin bireysel yaşamlarındaki krize yönelik algılarına ve anlamsızlık, belirsizlik ve yabancılaşma gibi duygularına göndermede bulunduğunu, dıştaki krizin ise onların toplumsal kurumlardaki ayrıcalıklı ve öncelikli konumunu kaybetmesiyle ilişkilendirildiğini ileri sürer. Bu kapsamda sağlık, çalışma yaşamı, aile ve eğitim gibi pek çok alandan gelen verileri bir araya toplayarak, bazı erkeklerin krize yönelik eğilimlerinden söz edilebilse de kapsamlı bir erkeklik krizinden söz edilemeyeceği konusunda Beynon'un görüşlerini destekler. ${ }^{10}$ Ancak bu durum Edwards'ın erkeklik krizini tamamen yadsımasını gerektirmez. Erkeklik krizine ilişkin farklı kuramsal açıklamaları temel alan yazar, yukarıdaki alanların aksine, üç düzeyde kapsamlı erkeklik krizinin savunulabileceğini belirtir. Bunlar; MacInnes'in ifade ettiği, bir değerler, pratikler ya da eğilimler seti olarak erkekliğin değerinin düşürülmesi ve onun pozitif özelliklerdense negatif özelliklerle ilişkilendirilmesi; toplumsal cinsiyet sınırlarının belirsizleşmesi ve son olarak erkekliğin krizin ta kendisi olduğunun savunulmasıdır. ${ }^{11}$

Bütün bu tartışmalar ışı̆̆ında, bu çalışmada benimsenen erkeklik krizi kavrayışının hem yapısal değişiklikleri göz önünde bulunduran hem de erkeklik performansı ve kriz söylemleri arasındaki ilişkiyi dikkate alan daha geniş bir erkeklik krizi kavrayışından yola çıktığı ifade edilebilir. Erkeklik krizinin erkeklerin topyekûn bir hâkimiyet kaybı anlamına gelmediği eleştirisini paylaşan bu çalışma, erkek karakterlerin hem toplumsal kurumlardaki ayrıcalıklı konumunu kaybetmesine (dıştaki kriz) hem de bu kayba yönelik algısına odaklanmasının (içteki kriz) yanı sıra krizin hegemonik erkekliğin yeniden üretim sürecinin bir parçası olması gibi öteki erkeklik krizi kavrayışlarının da erkeklik temsillerine etki etme biçimi üzerinde duracaktır. Böylelikle toplumdaki yapısal değişikliklerin erkeklik kavrayışları üzerinde yarattığı dönüşüme ek olarak, bireysel erkek öznelerin performansları aracılığıyla bu değişimlerin nasıl müzakere edildiğine odaklanarak erkeklik krizini daha ayrıntılı bir şekilde değerlendirmeye çalışacaktır.

\section{Sinemada Erkeklik Araştırmaları}

Nefes filmindeki erkeklik krizini ve erkekliğin inşasını ele alan bu çalışmada, üzerinde durulması gereken önemli bir nokta, psikanalizden beslenen erkekleri ve erkeklikleri ele alan film araştırmalarıdır. Sinemada erkeklik temsillerini çözümleyen araştırmacılar erkekliği şekillendiren sosyolojik ve kültürel süreçleri dikkate alan eleştirel erkeklik çalışmaları alanının yanı sıra cinsiyetlendirilmiş öznelliklerin karmaşalarını, kültür ve fantezi üretimiyle ilişkisini anlama imkânı sağlayan psikanalitik bir perspektiften de yararlanmışlardır. Çünkü psikanalitik kavrayış, cinsiyetlendirilmiş öznellikleri şekillendirmenin bilinçdışına ilişkin ruhsal süreçler tarafından merkezsizleştirildiğini gösterme suretiyle, ${ }^{12}$ kadınlığın erkekliğin ruhsal ötekisi olduğu toplumsal cinsiyetin ikili kültürel inşasını destekleyen ruhsal güçleri anlamaya imkân sağlamaktadır. ${ }^{13}$ Öznenin kültürün sembolik dünyasına ruhsal girişi ve cinsel farklılıkla ilişkileri kültürel kimliğin aynı zamanda cinsiyetlendirilmiş kimlik olduğunu gösterirken, ${ }^{14}$ psikanalitik teori diğer kültür teorilerinin yok saydığı bilinç dışı ruhsal süreçlerle ilişkili ortaya çıkan paradokslara dikkat çekmektedir. ${ }^{15}$

Sinemada erkeklik çalışmalarının gelişiminde de feminist film eleştirisinde olduğu gibi psikanaliz belirleyici olmuş; erkek öznellikleri bakış, özdeşleşme ve fantezinin yanı sıra histeri, mazoşizm, narsisizm, sadomazoşizm gibi psikanalitik kategoriler aracılığıyla tartışılmıştır. Erkekliğin basitçe bir hâkimiyet konumu 
olarak görülemeyeceğini vurgulayan bu çalışmalar aracılığıyla hem normatif erkeklik performanslarının üretilmesi bakımından sinemada kullanılan anlatım tekniklerine dikkat çekilmiş hem de bu performansları yapıbozumuna uğratan karşı-hegemonik pratikler dile getirilmiştir. Örneğin erkek mazoşizmi hem hâkim erkekliğin üretiminde hem de bertaraf edilmesinde devreye sokulan etkin bir pratik olarak değerlendirilmiştir. Kaja Silverman erkek mazoşizmini toplumsal cinsiyet düzenini bozguna uğratan bir karşı hegemonya pratiği olarak değerlendirirken, ${ }^{16}$ Paul Smith erkek üstünlüğünü ifade eden popüler anlatılarda mazoşizmin içerilme biçimlerine dikkat çekmiş ve mazoşizmin tek başına ilerici bir temsil örneği olarak görülemeyeceğini vurgulayarak mazoşist erkeklik performanslarının fillmlerin bağlamına göre değerlendirilmesinin gerekliliğini göstermiştir. ${ }^{17}$ Yine erkeklik çalışmaları bakımından üzerinde durulan bir diğer konu erkeklik krizi olmuş; erkekliğe ilişkin çalışmaların çoğunda beyaz, heteroseksüel erkek öznenin yabancılaşması ve parçalanması erkeklik krizi olarak tanımlanmıştır. ${ }^{18}$ Erkeklik krizinin toplumsal cinsiyet ilişkilerinin dönüşümü bakımından iki karşıt bakış etrafında tartışıldığı söylenebilir. Susan Faludi gibi bazı araştırmacılar, geç modernleşmede gerçekleşen dönüşümlerin ve belirsizliklerin negatif anlamda hegemonik erkeklik pozisyonlarını destekleyen bir kültürel geri tepmeye neden olduğunu savunurken; Segal ve Minsky gibi araştırmacılar pozitif bir biçimde erkekliğin farklı hallerinin daha az savunmacı erkekliklere yönelen karşı-hegemonik bir yapılanmaya işaret ettiğini ileri sürer. ${ }^{19}$ Bu noktada Caroline Bainbridge ve Candida Yates gibi yazarlar ise bu iki konumdan birinin benimsenmesinin zorunlu olmadığı söyleyerek alternatif bir bakış açısı ortaya koymuşlardır. Onlara göre, yapılacak analizde erkeklik krizini mutlak pozitif ya da negatif anlamda kuramlaştıran modelin ötesinde hareket etmek mümkündür. Bu bağlamda onların da belirttiği gibi, "günümüz erkekliklerindeki belirsizlikleri telaffuz etmekteki güçlüklere karşın, bütün fantezi, etki ve bilinçdışı arzuların birlikteliği ile bu belirsizliklerin araştırılmasında bir değer" vardır ve sinema "bunu araştıracak kullanışlı bir alan" sağlamaktadır. ${ }^{20}$

Yukarıda söylenenlerden hareketle, 2000'ler Türkiye sinemasında erkeklik krizini ve farklı erkekliklerin inşasını değerlendiren çalışmada filmleri çözümlemek için hem erkeklerin ruhsal ve toplumsal karmaşalarını tarihselleştiren perspektifleri hem de cinsiyetlendirilmiş izleyiciyi bir arada alma olanağı sağlayan sinepsikanaliz kullanılmakta $^{21}$ ve bu doğrultuda hem erkekliğin performe edilmesinde açığa çıkan krizleri ifade eden ve krizle mücadele etmek üzere devreye sokulan histeri, mazoşizm ve sadomazoşizm gibi psikanalitik kategorilerden, hem de Pat Kirkham ve Janet Thumim tarafından geliştirilen ve erkeklikleri çok boyutlu anlama imkânı sunan kavramsal terminolojiden yararlanılmaktadır. Bunları kısaca şu şekilde sıralamak mümkündür:

İç dünya: Kimliğin psişik inşasına ilişsin bilgi alanı olarak tanımlanabilir. Erkek olmak sembolik yapıya katılım gerektirir. Ancak bunun sembolik bir yapı olmasından ötürü gerçek deneyimin risklerini hesaba katmaması, her birey için eksikliği içerecek şekilde deneyimlenmesine neden olur ve bireyin kırılganlığı ve savunmasızlığı tanıması endişe üretir.

Dış dünya: İktidara ilişkin statü, hiyerarşi, bilgi, beceri ve başarı gibi konuları değerlendirme imkânı sunar.

Beden, eylem ve eylemsizlik: Erkeğin bedenini kullanma biçimi ve erkek bedeninin haz nesnesi olarak sunulması üzerinde yoğunlaşır.

Toplumsal cinsiyet politikaları: Toplumsal cinsiyet tanımlamalarının ve içerdiği ikili karşıtlıkların müzakere edilmesi olarak ifade edilebilir. ${ }^{22}$

Daha önce de belirtildiği gibi erkeklik psikanalitik sürecin yanı sıra toplumsal ve kültürel boyut çerçevesinde de şekillenmektedir. Dolayısıyla filmlerin içinden geçtiği tarihsel ve toplumsal bağlamın erkeklik temsilleri üzerindeki etkisinin göz önünde bulundurulması gerekmektedir. Bu kapsamda çalışmada çözümlenen erkekliğin bir kriz anlatısı çerçevesinde sorunsallaştırıldığı süreci neoliberal politikalar sonucunda sınıfsal uçurumun şiddetlendiği, eşcinseller, çevreciler, feministler, vicdani retçiler gibi çeşitli grupların demokratikleşme talepleri doğrultusunda kamusal alana çıktıkları ve etno-politik sorunlar çerçevesinde ulus devletin meşruiyetinin sorgulandığı 1980'lerden günümüze uzanan toplumsal kriz ve kutuplaşma süreciyle ilişkilendirmek mümkündür. Ayrıca Kürt sorununun çözümü konusunda 1990'larda uygulanan savaş siyasetinin ve 2000'lerde AKP hükümeti tarafından devreye sokulan ancak sembolik birtakım girişimlerle sınırlı kalan Kürt açılımının söz konusu erkeklik krizinin özel bağlamını oluşturduğu söylenebilir.

Çalışmanın odaklandığı 2000'li yıllarda Türkiye sinemasında üretilen temsillerin sözü edilen toplumsal kriz ortamına ilişkin travma, endişe ve hayal kırıklıklarını ele alış biçimiyle toplumsal anlam mücadelesi bakımından önemli bir potansiyel teşkil ettiği görülmektedir. Birçok genç yönetmenin sinemaya girdiği ve mevcut toplumsal sorunların filmlerde ifade olanağı bulduğu bu dönemde sinemanın konu alanı genişlemiştir. Hatta birçok çalışmada Türkiye sinemasının yarattığı bu potansiyel "yeni Türk sineması" tabiriyle ifade 
edilmeye başlanmıştır. Dolayısıyla çalışmanın sorunsalını oluşturan erkeklik temsilleri de döneme ilişkin toplumsal anlamların okunması ve bu anlamların dönüştürülmesi bakımından bir imkân sağlamıştır. Çalışmanın bundan sonraki bölümünde, bu temsil yapılanmasının ne anlama geldiğini yorumlamak üzere seçilen, savaş ve askerlik bağlamındaki erkeklik krizine yer veren Nefes filmi ele alınacak ve filmin topluma ve toplumsal cinsiyet ilişkilerine dair ne söylediği, hegemonik erkekliğe ilişkin değer, kural ve ayrıcalıkları yeniden üretip üretmediği sorgulanacaktır. Bu noktada çalışmada Nefes'e odaklanılmakla birlikte, Nefes'in militarizm, milliyetçilik ve erkeklik konusunda iç içe geçen ilişkiyi konu alan tek örnek olmadığını belirtmek gerekmektedir. Nefes'in yanı sıra savaşı ve savaş sonrası askerlerin yaşadığı travmayı anlatısının merkezine yerleştiren Yazı Tura (Uğur Yücel, 2004) ve Başka Semtin Çocukları (Aydın Bulut, 2008) da savaş ve askerlik çerçevesinde açığa çıkan erkeklik krizini sorunsallaştıran filmler arasında yer almaktadır.

\section{Hegemonik Erkeklik, Militarizm ve Erkeklik Krizi: Nefes Vatan Să̆olsun}

Nefes, 1993 yılında Güneydoğu'da sınır karakolunu korumakla görevli askerlere destek ekip sağlamak üzere dağlara doğru yola çıkan bir komando tugayının, dağda PKK tarafından pusuya düşürülmesi ve birisi komutanın yakın arkadaşı Orhan olmak üzere iki askerini kaybetmesi sonrasında gelişen travmatik olayları anlatmaktadır. Anlatısını üç sekans üzerinden yapılandıran filmin ilk sekansı dağa çıkışı ve askerlerin kaybıyla yaşanan travmayı merkeze alır. Çoğunlukla geriye dönük olarak inşa edilen ilk sekansta hem dağdaki pusu anına hem askerlerin tugaydaki görüntülerine hem de dağda zorlu geçen içtima sahnelerine yer verilir ve askerlerin geçirdikleri dönüşüm süreci vurgulanır. Filmin ikinci sekansında savaşa hazırlık dönemi görselleştirilir. Bu bölümün belirleyici temasını, komutanın, yakın arkadaşı Orhan'ın intikamını alma isteği oluşturmaktadır. Komutan karargâhın keşif haricinde karakoldan çıkmaması yönündeki emrine karşı gelmekte ve küçük bir ekip oluşturarak PKK'ya saldırı düzenlemektedir. Filmin son sekansında ise karakola yapılacak baskının askerler üzerinde yarattı̆̆ psikolojik gerilim, komutanın yaklaşan savaşla birlikte yaşadığı travmatik yarılma ve açı̆̆a çıkan erkeklik krizi savaş üzerinden kurgulanmaktadır.

Savaş filmlerinin türsel özelliklerini taşıyan Nefes, Anthony Easthope'un bu türe ait hâkim kodlamalar olarak adlandırdığı savaş, zafer, yenilgi ve erkek dostluğu temaları etrafında inşa edilmiştir. Bunları psikanalistler tarafından öngörüldüğü üzere, erkeksi egonun hâkimiyeti, hadım edilme korkusu, babalar ve oğullar ve erkek bağlılığının yüceltilmesi olarak tanımlamak mümkündür. ${ }^{23} \mathrm{Bu}$ çerçevede filmde de komutanın askerler ve kadın militan üzerinde uyguladığı sadizm ve düşmanla konuşmalarında öne çıkan rekabetçi eril dil erkeksi egonun hâkimiyetini açığa çıkarırken, savaştan korkan askerlerin halüsinasyon görmesi ya da yaralı askerlerin bedenleri hadım edilme tehdidini cisimleştirmekte, komutan ve askerler arasındaki ilişki zaman zaman baba-oğul ilişkisini hatırlatmaktadır. Ayrıca komutanın sadistik ve mazoşistik performanslar arasında bölünmesinde temel etkenin asker arkadaşı Orhan'a bağlılığı olması, erkek bağlılığının yüceltilmesini somutlaştırmaktadır.

Filmin sondan başa doğru yapılanan anlatısı "Karakola ne oldu" sorusunun cevabı üzerinden açımlanmaktadır. Bu çerçevede sonda yer alan yaralı ve ağlayan bir asker figürünün filmin başında görüntülenmesi bir yandan anlatıyla ilgili tedirgin edici bir beklenti duygusu yaratırken diğer yandan savaşla ilgili olarak histerik bir erkek bedeni üzerinden hegemonik erkeğin krizi etrafında gerçekleşecek bir tartışmaya zemin hazırlar. Filmin erkeklik krizi çerçevesinde devreye soktuğu önemli anlatısal odaklarından biri milliyetçilik ve militarizmle ilişkilidir. Bu bağlamda filmin yer verdiği erkeklik temsillerine geçmeden önce, filmin milliyetçiliğin eklemlendiği militarist değerler ve özellikle Türkiye'de şehitlik mertebesi aracılığıyla üretilen ve ölen askerlerin mitleştirilmesine neden olan kahramanlık ideolojisi bakımından farklı görüşler etrafında tartışıldığını belirtmek gerekir. Örneğin Sevilay Çelenk, askerlerin savaşa yönelik kararsızlığının kahraman erkekliğin yıkımını beraberinde getirdiğini ifade ederek, komutan tarafından dile getirilen savaşın haklı tarafı olmadığı görüşünü filmle ilgili anti militarist yoruma olanak sağlayan bir unsur olarak değerlendirirken, ${ }^{24}$ Nadire Mater, Senem Aytaç, Ayça Çiftçi gibi yazarlar filmin komutanın bakış açısından anlatısını inşa eden retoriğinin hem bireysel askerlerin söylemlerini hem de karşı tarafa yönelik bakış açısını sınırlandırdığına dikkat çekmekte ve filmdeki sembollerin kullanımının milliyetçilik ve militarizmle ilişkisine vurgu yapmaktadır. ${ }^{25}$ Aslında bu durumun filmin militarizm konusundaki çelişkili tutumundan kaynaklandığ düşünülebilir. Çünkü bir yandan askerlerin yaralanması ve öldürülmesi etrafında açığa çıkan kayıp duygusu ve komutanın karısına olan sevgisi nedeniyle ikircikli bir biçimde dile getirdiği "vatan sağ olsun" anlayışı savaşla ilgili ideolojik bir yorgunluk duygusunu ifade ederken, diğer yandan askerlerin çoğunun olumlu ahlaka ve 
yüceltilmiş bedenlere kavuşturulması, kurbanlaştırılmaları aracılığıyla mitleştirilmeleri, komutanın arkadaşının kaybından dolayı yaşadığı travmanın sadizm içeren eylemlerini meşrulaştırması ve savaşın retoriksel olarak kurtuluş mücadelesine bağlanması bu eleştirel olanağı kesintiye uğratmaktadır. ${ }^{26}$ Bunda filmin, Butler'ın ifade ettiği, yas hiyerarşisini kullanması da etkin bir rol oynar. ${ }^{27}$ Örneğin Butler bazı insanların ölümlerinin daha insanlaştırıldığını ifade ederek, genellikle evli ya da evlenmek üzere olan, heteroseksüel, mutlu ve tek eşli kişilerin yasının tutulduğunu, karşısındaki kişilerin ise kişisel tarihlerinin, isimlerinin, yüzlerinin ve ailelerinin söz konusu edilmediğini dile getirir. ${ }^{28}$ Bu bakış açısını filme uyarladığımızda, çatışmada öldürülen ve bir karısı, iki çocuğu ve bir arabası olan Orhan'ın ve ölümü karısının yere yığılışı paralelinde verilen komutanın yasının tutulduğu ancak doktor kod adlı Rıza ve son anda ismi söylenen Gulan dışındaki PKK militanlarının anlatıda isimlerinin bile telaffuz edilmediği ya da haklarında herhangi bir bilgi verilmediği görülür. Bu durum savaşın kötü olduğu söyleminin yalnızca askerler üzerinde yarattığı yıkım nedeniyle dile getirilmesine ve savaşın yalnızca evlerinden uzakta, iyi yürekli askerlerin ölümleri nedeniyle sorgulanabilir kılınmasına neden olur. ${ }^{29}$

Dolayısıyla Kürtlere yönelik açılım tartışmalarının gündeme geldiği dönemde çekilen film, Kürtlerin sesine yer veren sahneleriyle, askerlerin savaşçı kimliğindense kurban kimliğini ön plana çıkarmasıyla ve politik, toplumsal ve ekonomik meseleleri liberal bir bakışla hasıraltı eden söylemiyle kendisine farklılıkları eklemleyerek orduyu ve askerleri kutsayan resmi söylemin hegemonyasını yeniden üretmiş olur. ${ }^{30}$ Ayrıca filmde sık sık karşımıza çıkan Atatürk büstü ve fotoğrafları, kayaya kazınan ay yıldız, Osmanlı akıncılarının fotoğrafı ve bayrak gibi sembollerin kullanımı resmi ideolojiye yönelik bir eleştiri taşımaktan ziyade, vatanın kurtuluşu ve savunması için geçmişte ödenen bedellere dikkat çeker ve sınırı koruyan karakoldaki askerleri, daha önce yaşanılan kurtuluş mücadelesiyle ilişkilendirir. Örneğin filmin sonundaki çatışma sahnesinde sık sık Atatürk'ün kabartma şeklindeki bir imgesi kullanılırken, komutanın gözleri ile Atatürk’ün kanlanmış gözlerinin bir araya getirildiği ve böylece komutan ve Atatürk arasında bir özdeşlik yaratıldığı görülür. Yine komutanın traş olduğu sahnede Atatürk'ün fotoğrafi komutanın aynadaki yansımasıyla birleştirilmiştir. Senem Aytaç'ın da belirttiği üzere komutanın aynada yüzü bir an sağa kayınca kadrajda Atatürk'ün imgesi belirmektedir. ${ }^{31}$ Filmin sonunda çatışmadan yaralı kurtulan bir askerin karakolun dışına çıkar çıkmaz melodramatik dokunaklılığı sağlayan bir müzik eşliğinde Atatürk büstüne doğru topallayarak yürümesi ve büstü yerden kaldırarak güçlükle kucağında taşıdığının gösterilmesi ise erkek figürlerinin kendi öz yıkımları pahasına vatanı savunmaya devam edeceğini gösterir. Atatürk büstüyle birlikte kameranın çerçevesine giren "Ne Mutlu Türküm Diyene" yazısı savaş, vatan savunması, milliyetçilik ve gazilik gibi temel değerleri birleştirir. Film savaş nedeniyle histerikleşen ve travmaya uğrayan erkek bedenlerini gösterse bile filmin sonunda erkeklerin ödediği bu bedellerin ve kayıpların vatanı korumak için göze alındığı vurgusu milliyetçi ideolojiyi yeniden üretir. Ayrıca çatışma sahnesinin ardından pek çoğu ölen askerlerin karargâhta hep birlikte şarkı söylediği bir görüntünün devreye sokulması ve filmin başında söylenen komando marşının tekrar edilmesi askerlerin mitleştirilmesini ve yüce bir bedene yerleştirilmesini mümkün kılar.

Filmin erkeklik kriziyle ilgili devreye soktuğu önemli anlatısal odaklardan bir diğeri beyaz orta sınıf erkek öznenin, toplumda kendisine vaat edilen konum ve ayrıcalıklara ulaşamamasıyla ilişkilidir. Ancak bu kriz anlatısı ekonomik sistemin ve erkeğin hem hâkim hem de tabi olduğu ataerkil iktidar sisteminin sorgulanmasına neden olmaz. Erkekler arasındaki bağlılığı cisimleştiren yakın asker arkadaşın ölümünün erkeğin intikam almasını gerektirmesi, savaşın mazoşist bir gösteriye dönüştürülmesinin askeri eğitimin içerdiği şiddeti, sertliği ve disiplini meşru kılması, filmde savaş travması aracılığıyla erkeğin kadınsılaşması olarak tanımlayabileceğimiz bazı histerik tortular ${ }^{32}$ olsa bile, erkeğin görevinin ve belki de kaçınılmaz trajedisinin kendi ölümü ve sevdikleri pahasına vatanı kurtarma olduğu bilgisiyle geleneksel erkeklik değerlerini bir ideal olarak yeniden üretir. Bu noktada filmin askeri eğitime ve savaşa hazırlı dönemine ilişkin yaklaşımının, Fatih Özgüven gibi bazı eleştirmenlerin aralarındaki benzerliklere vurgu yaptı̆̆ ${ }^{33}$ Stanley Kubrick'in köklü bir militarizm eleştirisi barındıran Full Metal Jacket'ından (1987) farklılaştığını söylemek gerekir. Savaş karşıtı bir film olan Full Metal Jacket'ta askerlerin militarize edilmesi için kullanılan sert ve otoriter eğitimin ve ordunun her çeşit farklılığı dışlayan aşırı cinsiyetçi, ırkçı ve homofobik tutumunun askerleri intihara kadar götüren yıkıcı boyutları vurgulanırken, Nefes askeri eğitime ya da askeri hiyerarşiye yönelik herhangi bir eleştiri barındırmaz. Tersine askerlerin yürümeye alışması için koşturulduğunun söylendiği belgesel izlenimi veren görüntülerde komando eğitiminin zorunluluğu ön plana çıkarılır. Örneğin komutanın askerleri topladığı içtima sahnesinde, hata yaparlarsa cezalarının ölüm olacağına ilişkin sözü savaşın yarattığı dehşetten ve tedirginlikten dolayı anlayışla karşılanır. Çünkü savaş, bir ölüm kalım meselesidir ve böyle ağır bir eğitimden geçmeyen ya da hata yapan kişinin hayatta kalma şansı yoktur. 


\section{Kahraman Erkeklik}

Nefes'te gerek savaş sahneleri gerekse bir üst sesin eşlik ettiği belgesel etkisi taşıyan sahneler aracılığıyla militarizm, milliyetçilik ve hegemonik erkeklik değerleri arasındaki bağlantılar kurulurken kahramanlık ideolojisinin yıkılması ve yeniden üretilmesi biçiminde yorumlanabilecek çelişkili bir kavrayış ortaya konulur. Film bireysel erkek öznelerin savaşa ilişkin tereddütlerini ve savaş alanındaki yetersiz performanslarını göstererek kahramanlık ideolojisiyle ilgili eleştirel birtakım unsurlar barındırırken, aynı zamanda erkeklerin savaşçı olarak yeniden üretilmesine neden olan bu ideolojiyle açık biçimde hesaplaşılmasını engelleyen sözleri dolaşıma sokar. Filmde hem bu sıfatı hak etmenin zorluklarına işaret edilerek erkeklerin ödediği bedeller gösterilir hem de elinden geleni yapmasına karşın yıkıma uğrayan, kendisini topluluk değerleri için feda eden ve bu bağlamda ölümle eşitlenen askerlerin toplumda hak ettiği ilgiyi görmemesi eleştirilir. Bu durum, komutanın "45 saniyeliğine televizyonda kahraman olursunuz sonra da süslü püslü bir kadın magazin haberlerini sunmaya başlar” şeklindeki kadını küçümseyen eril dili aracılığıyla vurgulanır.

Filmde kahramanlık ideolojisini kesintiye uğratmayı engelleyen temel değerler, hegemonik erkeklik ve militarizmin karşılıklı birbirini pekiştirmesini sağlayan intikam, topluluk yararı, feragat, vatan savunması, kendini kurban etme, savaşçı yoldaşlığı ve erkek dostluğu gibi kavramlardır. Filmde ilk sahnelerden itibaren askerlerin birer kurbana dönüştürülmesi aracılığıyla kahramanlaştırılması sürecini izleriz. Ancak birçok savaş filminde olduğu gibi bireysel üstünlüğe dayalı bir süper güç hikâyesi temel alınmaz. Daha çok bireysel bedenlerin topluluk yararına feda edilmesi, erkeklerin toplum yaşamından ayrılması ve homososyal cemaate eklemlenmesi üzerinden bütün bir komando birliği kahramanlaştırılır. Bunda askerlerin gündelik yaşamı üzerine yapılan bir belgesel izlenimi veren ve komutanlarına ait bir üst sesin yorumladığı görüntülerin de etkisi vardır. Duygusal bir atmosfer yaratılmasına neden olan bu görüntüler, yaşanılan şeyin kurgu yerine gerçeğin ta kendisi olduğu izlenimi vermesinin yanı sıra erkeklerin komutana ait, aşkın bir üst ses aracılığıyla mitleştirilmesi- ve filmin sonunda kurbanlaştırılması- gibi bir işlevi de yerine getirir. Böylelikle askerlerin birer makine değil, özlemleri, sevinçleri, üzüntüleri olan sıradan insanlar olduğu vurgulanmakta ve onların eğitim sürecinden geçirilerek askeri hiyerarşiyi, disiplini ve dayanışmayı öğrenen ve bu süreçte toplumdan farklılaşan bir bütün haline getirildiklerine dikkat çekilmektedir. Ancak tam da bu bakış aracılığıyla erkekler arasındaki farklılıkları eriten, hepsini belirli erkeklik değerleri çerçevesinde aynılaştıran ve bu erkeklik değerlerini olumlayan bir söylem yeniden üretilir. Örneğin askerlerden birinin "adam olmak” için dağa çıkmak istemesi, çatışmada öldürülen diğerinin "kader kahramanını buldu" diyerek kahramanlaştırılması ve ötekinin "hata yaparlar ama asla yalan söylemezler" şeklinde özcü biçimde idealize edilmesi ve ahlaki açıdan olumlanması, erkekleri görevleri aracılığıyla askerlik ve savaş etrafında yüce bir bedene yerleştiren temel birtakım vurgular barındırmaktadır.

\section{Hegemonik Erkeğin Krizi: Sadomazoșist Performans ve Histeri}

Nefes'in merkezindeki figür, temsille ayrıcalıklı bir ilişkisi olan Mete komutandır. Komutanın bakış açısı çekimlerinden geçmişe yapılan geri dönüşler, belgesel etkisi taşıyan ilk sahnelerde ona aşkın bir otorite veren üst sesinin kullanılması, karısına yazdığı şiiri okurken duyulan iç sesi, duygusallığın ve erkekler arası mahremiyetin öne çıktığı sahnelerde ona zoom objektifle yaklaşılması/yakın çekimlerin devreye sokulması onun savaşla ilgili gözlemlerine, duygu ve düşüncelerine en çok ortak olunan kişi olmasını beraberinde getirir ve bu bağlamda izleyiciyle ayrıcalıklı bir ilişki kurmasını sağlar. İzleyicinin özdeşleşmek için çağrıldığı bir figür olur.

Yüzbaşı Mete figürü anlatıda ikili bir bakış doğrultusunda yapılandırılmıştır. Bir yandan arkadaşı Orhan'ın pusuda öldürülmesi üzerine erkek dostluğu ve intikam duygusu çerçevesinde saldırganlık ve şiddet aracılığıyla harekete geçirilen bir erkeklik performansı üstlenir. Diğer yandan ise yine bu ölümle birlikte toplumda kendisine vaat edilen orta sınıf erkeklik değerleriyle arasındaki mesafenin farkına varır ve orta sınıf erkek öznenin kurban edilmesi üzerinden, erkeklik krizi etrafında biçimlenen mazoşist bir yapıya eklemlenir. Bu bağlamda erkeğin acısını ve kayıplarını öne çıkartan film, onu melodramatik kılarak kurbanlaştırır. Juliana Schiesari melankolik ya da melodramatik erkeğin hem ataerkiye tepkili hem de onunla suç ortağı olduğunu ifade ederken, melankolik erkeği kadınsılıkla bağlantılı olduğu düşünülen acı ya da kayıpla özdeş bir figür olarak tanımlamakta ve kadınla ilgili melankolinin patoloji olarak kodlandığı yerde erkekteki melankolinin vicdan, 
yaratıcılık ve hassasiyet kılığında onun iktidarının dönüşümüne olanak tanıdığını belirtmektedir. ${ }^{34}$ Filmde de Orhan'ın ölümüyle tetiklenen bu melodramatik yapı filmin leitmotifi niteliğinde olduğu söylenebilecek, sıklıkla yüzbaşı tarafından dile getirilen "Orhan'ın bir karısı, iki çocuğu ve yeni aldığı bir arabası vardı" sözleri aracılığıyla tekrarlanır. Bu sözler baba olmak, evlenmek ve özel mülkiyete sahip olmak aracılığıyla beyaz orta sınıf erkek özneye önerilen ve hegemonik bir erkek idealini başarması için gerekli olan temel erkeklik değerlerinin ve ayrıcalıkların altını çizerken, erkeğin savaş nedeniyle gerçekleşen ölümüyle birlikte bu idealin kaybedilmesine dikkat çeker. Dolayısıyla bu kaybı melodramatik kılar. Ancak burada amaç erkekler üzerinde baskı yaratan ve onları hegemonik erkeklik değerleri etrafında performansa zorlayan ekonomik sistemin ya da ataerkil sistemin sorgulanması değildir. Daha çok erkeklerin bu değer ve ayrıcalıklara ulaşamaması nedeniyle ortaya çıkan kayıp duygusunun altı çizilir. Bununla birlikte erkeklerin bu idealden uzaklaşmasının tek nedeni savaş ya da ölüm olarak sunulmaz. Komutanın bankacı olan bir astsubay ile konuşmasında öne çıkan erkekler arasındaki gelir dağılımı eşitsizlikleri, vatan savunması yapan ve ulusun bütünlüğünü korumak adına kendi hayatını tehlikeye atan askerlerin ekonomik yoksunluğu ve herhangi bir özel mülkiyet edinmesinin güçlüğü de onların başarılı bir erkeklik performansı ortaya koymaları önünde engeldir. Bu durum kendilerine vaat edilen orta sınıf ayrıcalıkları ve değerleriyle aralarındaki mesafeyi artırır:

Komutan: Hakan bankaciydın de mi sen?

Hakan: Evet komutanım.

Komutan: Kamil, bak bu arkadaşlar senden de benden de beş kat fazla maaş alırlar. Öyle değil mi Hakan?

Hakan: Valla komutanım aydan aya değişiyo. Yani ikramiye falan da alıyoruz. Ama kesintiler de oluyo tabii.

Komutan: Peki ben ev kredisi için başvursam ne istersiniz benden?

Hakan: Ben krediler bölümünde değilim ama herhalde teminat isterler.

Komutan: E benim teminatım dağlar.

Hakan: Teminat gösterilecek şeyin sizin üzerinizde olması gerekir sanırım.

Komutan: Tapusu olmayınca bu dağlar bir bankacının gözünde beş para etmez, de mi?

Ayrıca filmde Orhan'ın ölümüyle açığa çıkan erkeklik krizi, komutanın ekonomik kayıplarının farkına varmasına ek olarak işi, ailesi, ülkesi kısaca toplumsal kimliği etrafında kurduğu bütünlüğün de parçalanmasıyla sonuçlanır. Bu travmatik kayıp onun hegemonik erkekliği cisimleştirme zorunluluğu nedeniyle o güne kadar bastırdığı çelişkilerini, endişelerini, acılarını ve hayal kırıklıklarını itiraf etmesine ve travmatik bedenden histerik bir bedene dönüşmesi aracılığıyla, kadınsılıkla ilişkili duyguları içeri almasına neden olur. Karısına daha önce onu sevdiğini söyleyemediği için pişmanlık duyar ve komando olmasının gerçek duygularını göstermesine engel olduğunu ifade eder: “Zeynep'e hiç söyleyemedim benim için ne kadar önemli olduğunu. Utandım. Komandoyuz ya biz. Öyle romantik şeylerle benim işim olmaz dedim kendime. Seni seviyorum diyemedim. Seni seviyorum. Ne kadar zor söylemesi on üç harfli kelimeyi." Çocukları olmadığını ve tedavi amacıyla ilaç kullandığını itiraf etmesi, erkeklik krizine babalık krizini eklemlemektedir. Ayrıca bu sahnede arkadaşı Orhan'ın ölümüne dayanamadığını vurgulayarak çatışmadan sağ çıkamayacağını söylemesi- hatta ilaçlarını almayı bırakması- ve karısına af dileyen bir mektup bırakması, intihar etme olasılığını hatırlatır. Vatanı korumak ve arkadaşının intikamını almak uğruna hem karısından hem de kendi yaşamından vazgeçer. Komutanın acısının ön plana geçirilmesi, onun mazoşist bir performans ortaya koymasına ve dolayısıyla askıda kalmasına neden olur: "Her şey kapkara Barış. Aradığım sorulara cevap bulamıyorum artık. Cevapsız kaldım bu dağlarda. Zeynep yok, Orhan yok. Her şey anlamsızlaştı. Bunu söylemeye cesaretim yok. Nasıl anlatırım burayı da Ankara kadar çok sevdiğimi."

Paul Smith mazoşist erkeğin büyük ölçüde fallik yasaya hizmet ettiğinden bahsederken, Lacan’a atıfla, mazoşizmin aslında kendini cezalandırmanın nevrozu olduğunu ifade eder. Çünkü mazoşizm kendisine sadistik vicdanın dönüşünü, süperegonun intikamını gerektiren bir yol belirlemektedir. Bu bağlamda mazoşistik an erteleme ve belirsizlik içerse de bu geciktirme yalnızca sonunda çözülmüşse çalışabilir. Dolayısıyla mazoşizm yasaya karşı gelmenin bir yolunu içerse bile aynı zamanda yasayla yolları ayırmamanın bir yolunu da içinde barındırmaktadır. Smith'in deyişiyle; “[m]azoşizmin kuralları, aslında metaforiktir ve oyun tartışmasız biçimde simgeselin esaretinde oynanan bir oyundur." 35 Bu nedenle çatışma sahnesinden önce erkeğin performansının savaş ve askerlik üzerinden, komutanın şu sözü aracılığıyla, yeniden üretilmesi gerekir: "Beni buraya siz gönderdiniz. En büyük asker bizim asker. Şehitler ölmez vatan bölünmez. Öyle bağırdı amcam. Halam bağırdı. 
Komşum bağırdı. Sen bağırdın. Ben de geldim [...] Bittiğinde beni yargılayacaksınız. Olsun yargılayın. Buradan başka gidecek yerim yok ki benim" ve "biz burada yenilirsek siz de Ankara'da, İstanbul'da yenilirsiniz" şeklindeki sözleri, savaşın topluluk yararı doğrultusunda harekete geçirildiğinin ve erkeklerin "ulusal bütünlüğü" korumak adına militarize edildiğinin altını çizer. Erkeklik militarizm ve milliyetçilikle eklemlenmiş, "biz ve onlar" karşıtlığından hareketle kazanma ve kaybetme oyununda sergilenen ve onaylanan bir performansa dönüşmüştür.

\section{Sadizm: Bir Erkeklik Ritüeli Olarak Mücadele ve Savaș}

Nefes'te komutan, gerek silahını kullanarak PKK militanlarını etkisiz hale getirdiği çatışma sahnesinde gerekse fiziksel gücünü kullanarak kadın militanın boğazını sıktığı işkence sahnesinde, şiddet ve fiziksel üstünlük aracılığıyla üretilen sadistik bir erkeklik performansı ortaya koymaktadır. "Mücadele, çatışma ve savaş bir erkeklik ritüelidir ve sonuna kadar dayanma mentalitesi, hem erkeğin kendi erkekliğini ispat etmesine, hem de başkalarının gözünde erkekliğin ifade edilmesine hizmet eder." ${ }^{\text {"6 }} \mathrm{Bu}$ sahnelerde komutan PKK'lıları ötekileştirerek onların bedenlerini hâkimiyeti altına alır. "Bedenin[in] bütünlüğü ötekinin bedeni tahrip edildiği zaman onaylanır." 37 Gerek bu sahnelerde gerekse komutan ve PKK militanı arasındaki karşılıklı konuşmalarda öne çıkan rekabet, kışkırtıcı bir dil aracılığıyla savaşı erkekler arasında gerçekleşen bir güç ve intikam mücadelesine çevirir. Bu konuşmalar savaşı cesaret/korkaklık üzerinden yeniden üretilen bireysel erkek performansına indirger. Komutan pusuda öldürülen arkadaşları, özellikle de yakın arkadaşı Orhan'ın intikamını alma güdüsüyle hareket ederken; PKK lideri de öldürüldüğünü düşündügüü kadın militanın intikamını almak ister.

Militan: Senden yoldaşımın ölümünün hesabını soracağım Kaya.

Komutan: Gel sor hadi.

Militan: O kadının intikamını alacağım senden.

Komutan: Ben de intikam alacağım.

Militan: O kadının heykelini dikicem oraya.

Komutan: Yiğit bir adam gibi gel.

Militan: Gelicem komutan çok az kaldı.

Komutan: Seni görmeden gitmem korkak herif.

Ancak filmde savaşan iki erkeğin performansına eşit şans tanınmadığı söylenebilir. Komutan anlatının yönlendiricisi konumundayken, Doktor kod adlı PKK militanı yalnızca fotoğrafta görünen, karanlık bir figüre ve tehdit edici bir sese indirgenir. ${ }^{38}$ Dolayısıyla iki erkek arasındaki karşıtlık, milliyetçilik söylemleri üzerinden harekete geçirilir. Komutan askerlerinden birine savaşta haklı taraf olmadığını ifade etse bile çatışma sahnesi bu söylemi tersine çevirmektedir. Filmi Türk askerlerinin bakış açısından izleyen ve askerlerin çatışmaya ilişkin tedirgin ve endişeli beklentisiyle özdeşleşen seyirci için katil olanlar Kürt militanlara, kurban konumunda olanlar ise Türk askerlerine dönüşmüştür. Dolayısıyla Higate ve Hopton'un da belirttiği gibi “ '[b]izim çocuklar' bize aittir ve '(yabancı) öteki' değildir; asker kimliği bu keskin ikili karşıtlık etrafında inşa edilir.” 39

Filmde komutan intikam alma arzusuyla karargâhın emirlerine karşı gelir, bireysel inisiyatif kullanarak eyleme geçer ve bir kadın teröristi yaralı ele geçirerek ona işkence yapar. Ayrıca filmin sonundaki çatışma sahnesinde kendi ölümü pahasına PKK liderini kadın militanla ilişkili konuşmalar yaparak kışkırtır ve onu tuzağa düşürür. Daha önce de belirtildiği gibi, bu sahnede komutan ölse bile rakibinin, yani PKK liderinin de ölmesini sağladığı için amacına ulaşmış, intikamını almış olur. Burada komutanı motive eden temel duygu savaşçı yoldaşlığıdır. Nira Yuval-Davis'in dile getirdiği üzere askerleri savaşa yönelten nedenler arasında ideolojik vatansever inançlar, maddi kazanç ya da statü ödülleri etkili olabilse de, savaşçıların günlük hayatlarını belirleyen asıl destekleyici duygu, "her zaman için yaşam ve ölüm durumlarında dost askerlere ve karşılıklı sadakate güvenebilme[ktir]." ${ }^{40} \mathrm{Bu}$ bağlamda filmin savaş etrafında harekete geçirilen anlatısında da, militarizmin ve erkekliğin karşılıklı olarak yeniden üretilmesini sağlayan eril bağlılık ve erkek dostluğu belirleyici bir rol oynar. Savaşta erkeklerin birbirlerine olan sevgisini itiraf etmesi, birlikte ağlaması ya da teselli bulması için birtakım olanaklar olduğunu belirten Easthope'un da vurguladığı gibi savaşta çekilen acı, erkek bağlılığının ifade edilmesi için ödenen bir bedel haline dönüşür. ${ }^{41}$ Ölüm ya da sakatlanma anı erkeklerin birbirlerine olan ihtiyacını ve sevgisini ifade etmesi için bir potansiyel sunar. ${ }^{42}$ Filmde de erkek dostluğu askerlik ve savaş gibi zorlu 
süreçlere katlanmada telafi edici bir mekanizma oluştururken, bu dostluğun kaybedilmesi kayıp ve eksiklik duygusu yaratır; erkeğin mazoşist ve sadist performanslar arasında bölünmesine neden olur.

Filmde komutanın karakola ulaştıktan sonra nöbette uyuyan bir askerle karşı karşıya kalması ve bunun üzerine birlikteki bütün askerleri savaşın ve ölümün ciddiyetini anlamaları için sert bir eğitim sürecine tabi tutması, hem sadizm hem de mazoşizm etrafında anlamlandırılabilecek izler barındırmaktadır. Karakola ulaştıktan sonra yüzbaşı ilk olarak oldukça gürültülü biçimde sobaya vurarak nöbette uyuyan askeri uyandırır. Komutanı karşısında gören asker hemen hazır ola geçerek ayağa kalkar. Askerin ayakkabısını giymeye bile firsatı olmamıştır. Kamera alt açıyla askerin ve yüzbaşının ayaklarını çekerken; askerin çıplak ayakları ve yüzbaşının postalları arasındaki karşıtlık, askerin komutanın otoritesine tabi oluşuna işaret ederek askerler arasındaki hiyerarşiye dikkat çeker. Daha sonra Mete yüzbaşı onu tekrar yerine oturtur ve geriye dönüşlerle, yakın arkadaşı Orhan'ın öldüğü çatışma sahnesini anlatmaya başlar. Farklı kamera açılarının devreye girmesiyle tekrar tekrar görüntülenen ve kameraya sıçrayan kanlarla birlikte oldukça stilize bir şiddet gösterisine dönüştürülen bu ölüm, bir yandan komutanın asker arkadaşının öldürüldüğü travmatik anda sabitlendiğini göstererek ondaki mazoşizmi açığa çıkarırken, diğer yandan askerleri ölümle korkutması aracılığıyla onlar üzerinde bir sadizm uygulamasını mümkün kılar. Bu yapıyı David Savran'ın Freud'dan hareketle geliştirdiği ve beyaz erkek öznenin eşzamanlı olarak kurban rolünü üstlenmesi ve reddetmesi aracılığıly üretildiğini belirttiği "refleksif sadomazoşizm" olarak tanımlamak mümkündür. Buna göre, öznenin egosunun sadist ve mazoşist bileşenlere ayrıldığ 1 refleksif sadomazoşizm, öznenin ötekilere işkence etme ve onlar üzerinde hâkimiyet kurma arzusunu kendisine geri çevirmekte ve bu arzu kendine-işkence etmeye ve kendini-cezalandırmaya dönüşmektedir. Savran'ın da belirttiği gibi öznenin bu ikili yapıyı üstlenmesi, itaati ve hâkimiyeti hem erotize etmesini hem de reddetmesini sağlayarak onu aynı anda saldırgan ve kurban, etkin ve edilgin, "erkeksi" ve "kadınsı" olabileceği bir çerçeve içine yerleştirmektedir. ${ }^{43}$ Filmde de komutanın askerleri cezalandırmak için tehditkâr bir tutumla gerek bıçağı askerin vücudunda gezdirmesi gerekse sobaya art arda vurarak kurşun seslerini yeniden canlandırması askerler üzerinde bir tehdit yaratmakta, ölümlerin askerler üzerindeki tahribatını pekiştirmektedir. Geriye dönük olarak yeniden inşa edilen bu sahne aynı zamanda komutanın asker arkadaşının ölümünden duyduğu acıyı ve üzüntüyü tekrar tekrar yaşamasını sağlamakta ve ondaki mazoşist yapıyı açığa çıkarmaktadır.

Komutanın askerlere sadistçe davrandığı içtima sahnesi de onun mazoşizmini ifade eder. Komutan askerleri topladığı bu eğitim sahnesinde, emir-komuta zincirinde göreve karşı gelmenin ya da görevi savsaklayarak yapmanın cezasının ölüm olduğunu belirtir. Askerlere aileleriyle ilgili sorular sorar ve yakınlarıyla duygusal bir özdeşlik kurmalarını sağlayarak onları mazoşist bir acı çekme deneyimine hapseder. Bu sahnede her erkeğe "koruması gereken topluluk kavramları çerçevesinde disiplin telkin ed[ilir]." ${ }^{44}$ Bu bağlamda erkek özneye aile içindeki sorumluluklarının hatırlatılması- örneğin ölmesi halinde karısının lojman hakkının elinden alınması gibi- erkek öznenin hegemonik erkeklik gereğince, aile içinde ve orduda üstlenmesi gereken görevleri arasında bir bağlantı kurulmasına neden olur. Böylece askerliğin gündelik hayattaki erkeklik mikro kültürüne ait pratiklere eklemlenmesi aracılığıyla, militarizm ve erkeklik karşılıklı olarak harekete geçirilmiş olur. Ayrıca komutanın askerlere "kahramanca mı savaştınız? Öyle mi öldünüz? Hayır. Bu adam uyudu diye öldünüz" ve "burası bir birlik. Bireysel hareket edemezsin. Arkadaşın için hareket edeceksin. Uyusun diye uyumayacaksın. Ölmesin diye öleceksin" diyerek hem askerliğin hem de erkekliğin temel kurallarını hatırlatması, "savaşçı yoldaşlığı" üzerinden pekiştirilen erkek homososyalliğini meşru kılar.

\section{Militarizmin Hizmetinde Kadınlar: Anne, Eş, Sevgili ve Militan Kadın İmgeleri}

Nefes'te olay örgüsü erkekler arasındaki mücadele ve dayanışma ekseninde belirlenirken; kadınların bu mücadelede sembolik bir rol oynadığı, daha çok erkek karakterlerin militarize edilmesi ve erkekliğini kadınların bakışında onaylaması çerçevesinde olumlandığı ya da namus çerçevesinde ötekileştirilerek dişarı atıldığı (abjection $)^{45}$ görülür. Çünkü Bourdieu'nün de belirttiği üzere rekabetin ciddi oyunlarının oynandığı erkek habituslarında kadınlardan beklenen temel rol izleyici konumuyla, hatta Virginia Woolf'a atıfla ifade ettiği gibi, erkeklerin güç ve üstünlüklerini gösteren yansıtıcı bir ayna olma işleviyle sınırlandırılır. ${ }^{46}$ Dolayısıyla kadınların bu işlevi karşılamadıkları noktada erkeklerin egemenliklerinin sorgulanmaya açık hale gelmesi ve erkeklik krizinin cisimleşmesi, filmde gördüğümüz üzere bu tehlikenin bertaraf edilmesini, kadının "namussallaştırılarak" ${ }^{47}$ cezalandırılmasını gerektirir. 
Filmde erkek karakterlerin militarize edilmesi etrafında araçsallaştırılan kadınların, üç temel rol çerçevesinde temsil edildiği görülmektedir. Bunlardan ilki, anne ya da eş olarak konumlandırılan kadınların askerler için endişelenen ya da onlara destek olanlar biçiminde militarize edilmesidir. Birçok feminist araştırmacı militarist hareketlerde kadınların "endişelenenler", erkeklerin ise "savaşçılar" biçiminde doğallaştırıldığından bahsederken, erkeklerin "kadınların aile ocağının ateşini yakmayı sürdürdükleri” bilgisiyle rahatlayıp savaşa motive olduğunu belirtirler. ${ }^{48}$ Filmde de komutanın askeriyle olan konuşmasında "bekleyen birinin olmasının iyi olduğu”na ilişkin vurgusu, militarize edilen kadınla ilişkili bu söylemi örnekler. Cynthia Enloe'nin sözleriyle, "kadınlar sıklıkla milliyetçi hareketlere katılmaya teşvik edilmişler, fakat rolleri erkek arkadaşlarının egolarını okşayan sevgili, stoik eş veya besleyen anne olmakla sınırlandırılmıştır." ${ }^{49} \mathrm{Bu}$ bağlamda askerlerin görevini bitirmesini ve geri dönmesini bekleyen "fedakâr" eş ya da sevgili rolünü üstlenenler ya da oğluna yönelik sevgisi, fedakârlığı ve sadakati nedeniyle yüceltilen ve anlatının duygusal atmosferini pekiştiren anneler, toplumsal cinsiyetlerinin gerektirdiği temel rolleri karşıladıkları ve savaştaki erkeklere destek oldukları için olumlanırlar. Askerlerin eşleri ya da sevgilileri özcü bir şekilde kadınsı duyarlılık ve zayıflıkla birleştirilirken, annelerin oğlu ölse bile "vatan sağ olsun" dedikleri vurgulanır. Anlatıda daha çok askerlerin telefon konuşmalarında sesleri aracılığıyla temsil edilen bu kadınlar arasında yer alan komutanın eşinin anlatının sonunda sesine ek olarak görüntüsüyle de varlık kazandığı görülür. Komutanın çatışmada vurulduğu ve karısının evde ölüm haberini beklediği sahneler paralel kurguyla, eş zamanlı olarak bir araya getirilir ve anlatının melodramatik ve travmatik etkisini pekiştirmek için kullanılır.

Askerdeki sevgilisine ya da eşine destek olmayan, kendi sıkıntılarından bahsederek savaştaki sevgilisinin ruhsal olarak zayıflamasına neden olan, alaycı bir dille erkeğin militarist politikalar doğrultusunda harekete geçirilmesini (ve savaşa konsantre olmasını) engelleyen bencil kadınlar ise aşağılayıcı bir dil aracılığıyla suçlanarak düşmana dönüştürülmektedir. Bu süreçte devreye sokulan en etkili mekanizma kadının aldatacağı imasıdır. Böylelikle namus üzerinden erkeklik söylemi harekete geçirilirken, kadının militarist politikaya ya da dile yönelik en ufak bir alaycı tavrı onun "namussallaştırılarak" dışa atılmasıyla sonuçlanır. Komutanın askeriyle yaptığı konuşma bu söylemi örnekler. Komutan bütün gece uyuyamadığını söyleyen Vedat'ın sorununun âşık olduğu kadınla ilgili olduğunu anlar ve ona "nerede yaşıyor" diye sorar. Vedat'ın "İstanbul'da" cevabını vermesi karşılığında ise "Biliyorsun büyük şehirlere aşk küçük gelir. Aldatacak oğlum seni" der. Böylelikle kent hayatının tehlikelerinin kadının fahişeleşmesi aracılığıyla metaforik bir dille anlatıldığı Yeşilçam filmlerinin kente ve kadına yönelik olumsuz çifte söylemi yeniden üretilir. Ayrıca asker ve sevgilisi arasındaki konuşmadan hemen sonra devreye sokulan ve askerlerin hep bir ağızdan söyledikleri şarkıda geçen kadına yönelik "fahişe" iması, "kötü sevgili figürünün” olumsuz imgesini destekler ve kadınlar karşısında kurulan erkek homososyalliğini harekete geçirerek erkekler arası dayanışma ve birliktelik söyleminin altını çizer. Şarkı şu şekildedir:

Bana bir resmini vermedin bi de.

Şimdi geziyorsun elden ele.

Çalacağım kapını bir demet gülle

İşte kapı çek git diyeceğim sokaklarına

Hayat kadını Allahsız sürtük

Biz seninle orda burada ne alem sürdük.

Bu sahnede izleyicinin kadın imgesine yönelik anlatı kodlarını yorumlaması büyük ölçüde hâkim okuma çerçevesinde kapatılmıştır. Çünkü kadının sıkıntı çektiğini söyleyip ilgisizlikten yakınması, "tabii sen bizi koruyorsun orada. Sen orda olduğun için ben huzurluyum” diyerek savaşı ve askerliği küçümsemesi, anlatıyı askerlerin bakış açısından izleyen ve onların maruz kaldıkları zorlu yaşam koşullarına ve sert eğitime tanık olan izleyicinin, kadını suçlayan erkeklik söyleminden yana olmasını beraberinde getirir. Kadının alaycı yaklaşımının askerlerin gerçek yaşamıyla tezat teşkil eden görüntüsü, bu söylemin tersine çevrilmesi aracılığıyla, askerlerin vatan savunması etrafında yüceltilmesine ve kadının ötekileştirilmesine neden olur.

Filmde olumsuz bir işlev yüklenen diğer kadın karakter ise hem askerlerin düşmanı olarak hem de toplumsal cinsiyet kimliği nedeniyle çifte ötekileştirmeye maruz kalan ve militarist politikalarla toplumsal cinsiyet politikaları arasındaki eklemlemeyi cisimleştiren Kürt kadın militandır. Bu bağlamda filmde kadın ve erkek militanın temsilinin hâkim toplumsal cinsiyet kodları çerçevesinde karşıtlaştığı, kadının savaşçı kimliğiyle erkekler arası mücadelede aktif bir konum alsa dahi özel alandaki ilişkiler üzerinden cinsiyetçi bir dille aşağılandığı ve böylelikle kamusal alandaki varlığının bertaraf edildiği görülür. Kürt erkek militan, intikamcı ve 
savaşçı gibi imgelerle yan yana getirilerek eylem içinde olan aktif bir düşmana dönüştürülürken -anlatıdaki militarist mücadelenin temel ekseni, komutan ve militanın temsilcileri olduğu erkekler arası güç ve üstünlük mücadelesidir- militan kadının "militan erkeğin sevgilisi”" olarak araçsallaştırılması aracılığıyla erkeğin intikam almasını gerektiren bir "nesneye" dönüştürüldüğü söylenebilir. ${ }^{50} \mathrm{Bu}$ doğrultuda filmde tek işkencenin bu Kürt kadın militana yapılması ve acı çeken, yaralı bedeninin ayrıntı çekim, yakın çekim, üst açılı çekim gibi farklı açılardan yapılan çekimler aracılığıyla nesneleştirilmesi ve uzunca bir süre izleyici bakışına sunulması Saigol'un ifadesiyle, düşman olarak tanımlanan bir yabancının, kimliği tehdit ettiği her noktada kadın bedeninin en şiddetli çatışma alanlarına dönüştüğünün bir göstergesi haline gelir. ${ }^{51}$ Üstelik bu sahnede kadın militanın, bedeninin işkenceye tabi tutulmasının yanı sıra toplumsal cinsiyetinden ötürü cinsiyetçi ve pornografik bir dille de aşağılandığı görülür:

Komutan (Kadının boğazını sıkmaktadır): Orhan’ın ve Emre'nin şehit düştüğü pusuda sen de var mıydın? Orada mıydın? Orhan'ın bir karısı, iki çocuğu ve bir de yeni aldığı arabası vardı. Öldürülüşlerini gördün mü? Seyrettin de mi? Senin bekleyenin yok mu kızım? Sen ölürsen kim üzülür? Ben üzülmem. Sikiyo değil mi seni? Sikiyo. O doktoru getiricem buraya.

Kadını tedavi eden doktor: Komutanım öldüreceksiniz.

Komutan: Bi sus.

Asker: Doktor sizi anons ediyor.

Komutan: "Komutanım sevgilinle ilgileniyor", "birazdan gelicek" de. Bak tanıyormuşsunuz birbirinizi. Doktor nerde?

Doktor: Komutanım öldüreceksiniz.

Komutan (Doktorun boğazını sıkar): Doktor buradaymış.

Barış: Komutanım yeter.

Komutan: Bir karısı, iki çocuğu bir de yeni aldığı arabası vardı Orhan'ın.

Bu sahneyle ilgili üzerinde durulması gereken bir diğer nokta kadına yönelik işkencenin arkadaşına ve karısına olan bağlılığıyla anlatıda olumlanan/kurbanlaştırılan/mazlumlaştırılan komutan tarafından gerçekleştirilmesi ve bu işkencenin düşmanı konuşturmak ya da ondan intikam almak için gerçekleştirilen bir eylem olarak sunulması aracılığıyla meşrulaştırılmasıdır. Bu doğrultuda komutanın işkencenin başında ve sonunda düşman tarafından öldürülen Orhan'dan bahsetmesi, işkence eyleminin duygusal bir içerik katılarak sorgulanmamasını mümkün kılar.

\section{Sonuç}

2000’ler Türkiye sinemasında erkeklik krizinin temel görünümlerinden biri kurbanlaşmadır ve bu filmlerde erkek karakterlerin kurban olarak sunulmasının erkeklik krizi bakımından temel olarak iki farklı söyleme hizmet ettiği görülmektedir. Bunlardan birincisi, 1990 sonrasında Türkiye'nin geçirdiği siyasi, ekonomik ve toplumsal dönüşümler sonucunda hâkimiyet konumu sarsılan erkek karakterlere yönelik bir sempati yaratılması ve erkek karakterlerin mazlum öznelere dönüştürülmesi yoluyla erkeklik kayıplarının bir haksızlık olarak deneyimlenmesinin mümkün kılınmasıyken; ikincisi kurbanlaşmanın erkek karakterlerin erkekliği performe ederken karşı karşıya kaldığı travmatik deneyimlere göndermede bulunması ve böylelikle hâkim toplumsal cinsiyet ilişkilerinin sorgulanmasına yönelik anlamlar barındırmasıdır. ${ }^{52} \mathrm{Bu}$ noktada çalışmada çözümlenen Nefes'in bunlardan ilkini temsil ettiği, filmin hegemonik erkeklik değerlerine ilişkin bazı sorgulamalar barındırmakla birlikte onları tamamen geçersizleştirmek yerine, savaşçı yoldaşlığı, intikam, kurbanlaşma ve feragat üzerinden yeniden ürettiği söylenebilir. Filmde erkeklik krizi bireysel erkek öznenin aşırı erkeklik performansı ya da yeterli erkeklik performansını cisimleştirememesi aracılığıyla sergilenirken, melodramatik bir söylem etrafında kapatılarak kurbanlaşma ve kefaret gibi unsurlarla ilişkilendirilir ve erkeklerin hegemonyasının yeniden kurulmasına yönelik bir arzuya kaynaklık eder. Dolayısıyla erkeklerin hâkimiyeti yeniden elde etmesine yönelik bir onay yaratılır. 
${ }^{1} \mathrm{Bu}$ makale, Ankara Üniversitesi Sosyal Bilimler Enstitüsü Radyo Televizyon Sinema Anabilim Dalı'nda tamamlanan “2000'ler Türkiye Sinemasında Erkeklik Krizi ve Erkek Kimliğinin İnşası” başlıklı doktora tez çalışmasının bir bölümü temel alınarak hazırlanmıştır.

${ }^{2} \mathrm{Bu}$ filmlerin belli başlıları şu şekilde sıralanabilir: Deli Yürek Bumerang Cehennemi (Osman Sınav, 2001), Kurtlar Vadisi Irak (Serdar Akar, 2005), Son Osmanlı Yandım Ali (Mustafa Şevki Doğan, 2006), Kurtlar Vadisi Filistin (Zübeyr Şaşmaz, 2010).

${ }^{3}$ Anthony Easthope, What a Man's Gotta Do: The Masculine Myth in Popular Culture (Boston: Unwin Hyman, 1990), 2.

${ }^{4}$ Michael S. Kimmel, R.W. Connel and Jeff Hearn (ed.), "Introduction," Handbook of Studies on Men and Masculinities ( Thousand Oaks, London \& New Delhi: Sage, 2005), 1.

${ }^{5}$ Kimmel, Connel and Hearn (ed.) "Introduction," 7.

${ }^{6}$ R. W. Connell, "Masculinities and Men's Health," Gender in Interaction: Perspectives on Femininity and Masculinity in Etnography and Discourse ed. Bettina Baron and Helga Kotthoff (Amsterdam \& Philadelphia: John Benjamins, 2001), 141 - 142.

${ }^{7}$ John MacInnes, The End of Masculinity: The Confusion of Sexual Genesis and Sexual Difference in Modern Society (Buckingham: Open University Press, 1998), 47- 55.

${ }^{8}$ R. W. Connell, “On Hegemonic Masculinity and Violence: Response to Jefferson and Hall," Theoretical Criminology 6, no. 1 (2002).

${ }^{9}$ John Beynon, Masculinities and Culture (Buckingham: Open University Press, 2002), 96.

${ }^{10}$ Tim Edwards, Cultures of Masculinity (London \& New York: Routledge, 2006), 8, 14.

${ }^{11}$ Edwards, Cultures of Masculinity, 14.

${ }^{12}$ Rosalind Minsky, Psychoanalysis and Gender (London\& New York: Routledge, 1996).

${ }^{13}$ Candida Yates, Masculine Jealousy and Contemporary Cinema (New York: Palgrave Macmillan, 2007), 7.

${ }^{14}$ Benvenuto ve Kennedy'den aktaran Yates, Masculine Jealousy and Contemporary Cinema, 7.

${ }^{15}$ Yates, Masculine Jealousy and Contemporary Cinema, 7.

${ }^{16}$ Kaja Silverman, Male Subjectivity at the Margins (New York and London: Routledge, 1992).

${ }^{17}$ Paul Smith, "Eastwood Bound," Constructing Masculinity ed. Maurice Berger, Brian Wallis and Simon Watson (New York \& London: Routledge, 1995).

${ }^{18}$ Pam Cook and Mieke Bernink. The Cinema Book (London: BFI, 2005), 362.

${ }^{19}$ Aktaran Caroline Bainbridge and Candida Yates, "Cinematic Symptoms of Masculinity in Transition: Memory, History and Mythology in Contemporary Film," Psychoanalysis, Culture and Society 10 (2005): 300.

${ }^{20}$ Bainbridge ve Yates, "Cinematic Symptoms of Masculinity in Transition,” 300.

${ }^{21}$ Yates, Masculine Jealousy and Contemporary Cinema, 55- 56. 
${ }^{22}$ Pat Kirkham ve Janet Thumim, "Me Jane," Me Jane: Masculinity, Movies and Women ed. Pat Kirkham and Janet Thumim (New York: St. Martin's Press, 1995).

${ }^{23}$ Easthope, What a Man's Gotta Do, 63.

${ }^{24}$ Sevilay Çelenk, "Yasak Yas, Kesik Nefes,” Birikim 249 (2010): 93.

${ }^{25}$ Fırat Yücel vd., Yuvarlak Masa Tartışması: "Nefes Vatan Sağolsun,” Altyazı 90 (2009) ve Emre Aköz, "Unutmamalıyız ki Milliyetçilik Savaştır," Nadire Mater'le söyleşi, Sabah e- Gazetesi, $25 \quad$ Ekim 2009 , http://www.sabah.com.tr/Ekler/Pazar/Guncel/2009/10/25/unutmamaliyiz_ki_milliyetcilik_savastir.

${ }^{26}$ Fatih Özgüven Nefes'in komutanı merkeze alan bir yıpranma hikâyesi sunduğunu ve "vatan sağ olsun” derken kesilen nefesi ön plana çıkarttı̆̆ını belirtirken (Özgüven, "Kesilen 'Nefes," 2009); Nadire Mater filmin, meselesini tereddüt içinde sunan, farklı görüşlere yer veriyormuş gibi yaparak eninde sonunda ölümü, savaşı ve militarizmi kutsayan bir söylem içerdiğini ileri sürmektedir. Aköz, "Unutmamalıyız ki Milliyetçilik Savaştır."

${ }^{27}$ Türkiye bağlamında ölen asker bedenlerinin dramatik anlatılarda en az PKK militanları kadar temsil olanağının sınırlı olduğunu ifade eden Çelenk'in Nefes filminin bu konuda bir kırılma yarattığına ilişkin yorumu için bkz, Çelenk, "Yasak Yas, Kesik Nefes,” 90 97.

${ }^{28}$ Judith Butler, Kırılgan Hayat: Yasın ve Şiddetin Gücü, çev. Başak Ertür (İstanbul: Metis, 2005), 46-47.

${ }^{29}$ Bu noktada Nefes 'in savaşa yönelik söyleminin Vietnam savaşına ilişkin liberal filmlerin bakış açısıyla örtüştüğü görülebilir. Ryan ve Kellner liberal filmlerin bireysel bakışı öne çıkarırken, tarihsel sorunları bir yana bıraktığını ve savaşı iyi yürekli, beyaz Amerikan gençlerinin yaşamını altüst ettiği için eleştirdiğini ifade ederler. Liberallerin genel olarak orduyu eleştirmekten kaçındığını ve kişiselci bir anlatımı benimsediğini belirten yazarlar, bunun ulusal politikalara yönelik tepkiden çok kişisel acılar karşısında duygusal sonuçlar yarattığını vurgular. Michael Ryan ve Douglas Kellner, Politik Kamera: Çağdaş Hollywood Sinemasının İdeolojsi ve Politikası, çev. Elif Özsayar (İstanbul: Ayrınt1, 2010), 307, 310.

${ }^{30}$ Ayrıca burada komutanın yalnızca savaşmakla kazanılamayacağını bildiği Kürt sorununa yönelik kullandığı "bir gün savaş bitecek ve bittiğinde beni yargılayacaksınız. Olsun yargılayın. Buradan başka gidecek yerim yok ki benim" ya da "keşke beni biraz daha fazla sevebilseydiniz" gibi sözleri Güneydoğu'da savaşan ancak hak ettiği ilgi, sevgi, hoşgörü ve değeri görememesinin yanı sıra belki de savaştı̆̆ için yargılanan bir askerin kendisini kurbanlaştırarak cisimleştirdiği, arkasında gelecekte değerinin ve haklılığının anlaşılacağına inanan bir askerin gizli inancını taşıyan toplumsal mazoşizmden söz etmek mümkündür. Reik'ın toplumsal mazoşizme ilişkin ifadesini ödünç alacak olursak; “[b]u kadar çok acı çeken, daha sonra seçilmişlerin arasında olacaktır; onlar başkalarından üstündür ve onların er ya da geç dünyanın takdir edeceği bir görevi vardır.” Theodor Reik, Aşk ve Şehvet Üzerine: Romantik ve Cinsel Duyguların Psikanalizi, çev. Ali Kılıçlığlu (İstanbul: Say, 2006), 397.

${ }^{31}$ Yücel vd., "Nefes Vatan Sağolsun,” 83.

${ }^{32}$ Paul Smith Clint Eastwood'un bazı filmlerinden hareketle, popüler anlatılarda erkek karakterlerin çelişkilerine dair çözümlenmemiş, anlatısal kapanmanın sınırlarını aşan, anlatı süreçleri tarafından kontrol edilemeyen birtakım semptomların varlığından bahseder ve bunları erkek histerisinin ısrarlı temsillerine işaret eden histerik tortular olarak adlandırır: "Bu tarz bir temsili çerçevede, bir şeyler kaçar ya da kontrolsüz kalır. Histerik fallik sınırı aşan, üstünden atlayandır. Histerik, ket vurmadan yoksun oluşuyla, bedenin ağrılarını ya da utançlarını talep edişiyle ve erkek deneyiminde söylenmeyeni taşıma göreviyle belirlenir.” (Smith, “Eastwood Bound,” 79-80). Bu bağlamda Nefes'te de erkeğin intikam almak için kendisini kurbanlaştırması -ölümü seçerek kendisini feda etmesi- hegemonik erkeklik değerleri etrafında bir kapanım sağlasa da, komutanın karısına, asker arkadaşına, 
doğmamış çocuğuna yönelik duygularını itiraf ederek histerik bir performans ortaya koyması erkekliğin doğuştan getirilen bir bütünlük olmadığının altını çizer ve arkasında birtakım histerik tortular bırakır.

${ }^{33}$ Özgüven, “Kesilen 'Nefes.’”

${ }^{34}$ aktaran Kathleen Rowe, "Melodrama and Men in Post-Classical Romantic Comedy," Me Jane: Masculinity, Movies and Women ed. Pat Kirkham and Janet Thumim (London: Lawrence \& Wishart, 1995), 186.

${ }^{35}$ Smith, "Eastwood Bound," 90- 91.

${ }^{36}$ Hilal Onur ve Berrin Koyuncu, “'Hegemonik’ Erkekliğin Görünmeyen Yüzü: Sosyalizasyon Sürecinde Erkeklik Oluşumları ve Krizleri Üzerine Düşünceler,” $\quad$ Toplum $\quad$ ve $\quad$ Bilim $\quad 101 \quad$ (2004): 40.

${ }^{37}$ Easthope, What a Man's Gotta Do, 65

${ }^{38}$ Yücel vd., "Nefes Vatan Sağolsun,” 83 ve Nermin Yıldırım, "Kimin “nefes’i,” Radikal 2, 1 Kasım 2009, http://www.radikal.com.tr/Radikal.aspx?aType=RadikalEklerDetayV3\&ArticleID=962213\&CategoryID=42

${ }^{39}$ Paul Higate and John Hopton, "War, Militarism, and Masculinities," Handbook of Studies on Men \& Masculinities ed. M. S. Kimmel, J. Hearn and R.W. Connell (Thousand Oaks, London and New Delhi: Sage, 2005), 441.

${ }^{40}$ Nira Yuval-Davis, Cinsiyet ve Millet, çev. Ayşin Bektaş (İstanbul: İletişim, 2003), 201.

${ }^{41}$ Easthope, What a Man's Gotta Do, 66.

${ }^{42}$ Roger Horrocks, Masculinity in Crisis: Myths, Fantasies and Realities (London: Macmillan, 1994), 150-151.

${ }^{43}$ David Savran, The Sadomasochist in the Closet: White Masculinity and the Culture of Victimization," Differences: A Journal of Feminist Cultural Studies 8, no. 2 (1996): 127- 129.

${ }^{44}$ Cynthia Cockburn, Buradan Baktığımızda: Kadınların Militarizme Karşı Mücadelesi, çev. Füsun Özlen (İstanbul: Metis, 2009), 298.

${ }^{45}$ Julia Kristeva tarafından geliştirilen abjection (iğrençlik, dışlama, dışa atma) kavramı, bir grubun ya da öznenin kimlik sınırlarını tehdit eden her şeyi dışlamasına ilişkin bir psikolojik tepkiyi ifade ederken, Iris Marion Young kavramın kullanımını genişletmiş, onu ırkçılık, homofobi, cinsiyetçilik gibi her türlü ayrımcılık biçimini açıklamak için yaygın bir başvuru noktası haline getirmiştir. Nil Mutluer, “Türkiye'de Cinsiyet Hallerinin Sınırları: 'Namussallaştırma,"” Cinsiyet Halleri ed. Nil Mutluer (İstanbul: Varlık, 2008 ), 15. Buna göre; "cinsiyetçilik, homofobi ve ırkçılık, yani bedenleri cinsiyetleri, cinsellikleri ve/veya renkleri nedeniyle reddetmek bir 'dışarı püskürtme' edimidir, bunu takip eden 'geri püskürtme' edimi ise kültürde hegemonik olan kimlikleri cinsiyet/1rk/cinsellik bazlı farklılaştırma eksenlerine göre kurar ve pekiştirir.” Judith Butler, Cinsiyet Belası: Feminizm ve Kimliğin Altüst Edilmesi, çev. Başak Ertür (İstanbul: Metis, 2008), 221.

${ }^{46}$ Bourdieu'den aktaran Onur ve Koyuncu, “'Hegemonik’ Erkekliğin Görünmeyen Yüzü,” 33. 
${ }^{47}$ Namusla ilişkili bir konunun tabu sayılarak dışlanmasından hareketle geliştirilen "namussallaştırma”, iktidarın tehdit algıladığı bir konuyu yok saymasını mümkün kılan bir strateji olarak değerlendirilebilir. Bkz, Mutluer, "Türkiye'de Cinsiyet Hallerinin Sınırları," 23-24.

${ }^{48}$ Yuval-Davis, Cinsiyet ve Millet; Cynthia Enloe, Muzlar, Plajlar ve Askeri Üsler: Feminist Baklş Açısından Uluslararası Siyaset, çev. Berna Kurt ve Ece Aydın (İstanbul: Çitlenbik, 2003).

${ }^{49}$ Enloe, Muzlar, Plajlar ve Askeri Üsler, 99.

${ }^{50}$ Ayrıca doktorun yaralı olarak ele geçirilen kadın militanın kanamasını durdurmaya çalıştığı sırada odada bulunan televizyonda Türkiye güzeliyle yapılan röportaj, iki farklı gerçeklik düzlemini yan yana getirir. Bu sahnede bir yanda yarışmaya nasıl hazırlandığını ve hâlâ bir rüyada olduğunu anlatan Türkiye güzeli ve diğer yanda kesik kesik soluyan ve can çekişen kadın militan arasında görsel ve işitsel bir karşıtlık kurulmuş ve bu karşıtlık üzerinden bir yabancılaşma etkisi yaratılmıştır. İlerleyen çekimlerde Kürt militana müdahalede bulunan doktorun rahatsız olup televizyonun kapatılmasını istemesi de izleyicinin dikkatini bu karşıtlı̆̆a çekmektedir.

${ }^{51}$ Rubina Saigol, "Militarizasyon, Ulus ve Toplumsal Cinsiyet: Şiddetli Çatışma Alanları Olarak Kadın Bedenleri,” Vatan Millet Kadınlar ed. Ayşe Gül Altınay (İstanbul: İletişim, 2004), 255.

${ }^{52}$ Örneğin Başka Semtin Çocukları ve Yazı Tura gibi filmler savaşçı kimliğini sorunlaştırmaları bağlamında bu söyleme hizmet ederler. Erkek öznenin vatan savunması uğrunda ödediği bedelleri herhangi bir üstünlük ya da kahramanlık ibaresi olmaksızın ifade eden ve savaştan evine dönen erkeklerin travmatik kayıplarını sergileyerek, erkeklik ve savaşçı kimliği arasındaki doğallaştırılmış eklemlenmenin altını oyan bu filmler milliyetçilik, militarizm ve erkeklik arasında iç içe geçen ilişkinin sorgulanmasına imkân sağlarlar.

\section{Kaynaklar}

Aköz, Emre, "Unutmamalıyız ki Milliyetçilik Savaştır,” Nadire Mater'le söyleşi, Sabah e- Gazetesi, 25 Ekim 2009, http://www.sabah.com.tr/Ekler/Pazar/Guncel/2009/10/25/unutmamaliyiz_ki_milliyetcilik_savastir

Ashcraft, Karen Lee and Lisa A. Flores. "Slaves With White Collars': Persistent Performances of Masculinity in Crisis,” Text and Performance Quarterly 23, no. 1 (2003): 1-29.

Bainbridge, Caroline and Candida Yates. "Cinematic Symptoms of Masculinity in Transition: Memory, History and Mythology in Contemporary Film,” Psychoanalysis, Culture and Society 10 (2005): 299- 318.

Beynon, John. Masculinities and Culture (Buckingham: Open University Press, 2002).

Butler, Judith. Kırılgan Hayat: Yasın ve Şiddetin Gücü, çev. Başak Ertür (İstanbul: Metis, 2005).

Butler, Judith. Cinsiyet Belası: Feminizm ve Kimliğin Altüst Edilmesi, çev. Başak Ertür (İstanbul: Metis, 2008).

Cockburn, Cynthia. Buradan Baktığımızda: Kadınların Militarizme Karşı Mücadelesi, çev. Füsun Özlen (İstanbul: Metis, 2009).

Cohan, Steven and İna Rae Hark. "Introduction," Screening the Male: Exploring Masculinities in Hollywood Cinema ed. Steven Cohan and Ina Rae Hark (London: Routledge, 1993), 1- 8.

Connell, R. W. "Masculinities and Men's Health," Gender in Interaction: Perspectives on Femininity and Masculinity in Etnography and Discourse ed. Bettina Baron and Helga Kotthoff (Amsterdam and Philadelphia: John Benjamins, 2001), $139-152$.

Connell, R. W. “On Hegemonic Masculinity and Violence: Response to Jefferson and Hall,” Theoretical Criminology 6, no. 1 (2002): 89- 99.

Cook, Pam and Mieke Bernink. The Cinema Book (London: BFI, 2005). 
Çelenk, Sevilay. "Yasak Yas, Kesik Nefes," Birikim 249 (2010): 90- 97.

Easthope, Anthony. What a Man's Gotta Do: The Masculine Myth in Popular Culture (Boston: Unwin Hyman, 1990).

Edwards, Tim. Cultures of Masculinity (London: Routledge, 2006).

Enloe, Cynthia. Muzlar, Plajlar ve Askeri Üsler: Feminist Bakış Açısından Uluslararası Siyaset, çev. Berna Kurt ve Ece Aydın (İstanbul: Çitlenbik, 2003).

Higate, Paul and John Hopton. "War, Militarism, and Masculinities," Handbook of Studies on Men \& Masculinities ed. M. S.

Kimmel, J. Hearn and R.W. Connell (Thousand Oaks, London \& New Delhi: Sage, 2005), 432- 447.

Horrocks,Roger. Masculinity in Crisis: Myths, Fantasies and Realities

(London: Macmillan, 1994).

Kimmel, Michael S. vd. (ed.). "Introduction," Handbook of Studies on Men and Masculinities ( Thousand Oaks, London \& New Delhi: Sage, 2005), 1- 12.

Kirkham, Pat and Janet Thumim. "Me Jane," Me Jane: Masculinity, Movies and Women ed. Pat Kirkham and Janet Thumim (New York: St. Martin's Press, 1995), 11- 35.

MacInnes, John. The End of Masculinity: The Confusion of Sexual Genesis and Sexual Difference in Modern Society (Buckingham: Open University Press, 1998).

Minsky, Rosalind. Psychoanalysis and Gender (London: Routledge, 1996).

Mutluer, Nil. "Türkiye'de Cinsiyet Hallerinin Sınırları: 'Namussallaştırma," Cinsiyet Halleri ed. Nil Mutluer (İstanbul: Varlık, 2008), 14- 30 .

Onur, Hilal ve Berrin Koyuncu. “ 'Hegemonik’ Erkekliğin Görünmeyen Yüzü: Sosyalizasyon Sürecinde Erkeklik Oluşumları ve Krizleri Üzerine Düşünceler,” Toplum ve Bilim 101 (2004): 31- 49.

Özgüven, Fatih. “Kesilen 'Nefes,”” Radikal e-Gazetesi, 22 Ekim 2009,

http://www.radikal.com.tr/Radikal.aspx?aType=RadikalYazar\&Date=22.10.2009\&ArticleID=960468\&CategoryID=113

Reik, Theodor. Aşk ve Şehvet Üzerine: Romantik ve Cinsel Duyguların Psikanalizi, çev. Ali K1lıçlığlu (İstanbul: Say, 2006).

Rowe, Kathleen. "Melodrama and Men in Post-Classical Romantic Comedy," Me Jane: Masculinity, Movies and Women ed. Pat Kirkham and Janet Thumim (London: Lawrence \& Wishart, 1995), 184-193.

Ryan, Michael ve Douglas Kellner. Politik Kamera: Çağdaş Hollywood Sinemasının İdeolojsi ve Politikası, çev. Elif Özsayar (İstanbul: Ayrınt1, 2010).

Saigol, Rubina. "Militarizasyon, Ulus ve Toplumsal Cinsiyet: Şiddetli Çatışma Alanları Olarak Kadın Bedenleri," Vatan Millet Kadınlar ed. Ayşe Gül Altınay (İstanbul: İletişim, 2004), 227- 259.

Savran, David. "The Sadomasochist in the Closet: White Masculinity and the Culture of Victimization," Differences: A Journal of Feminist Cultural Studies 8, no. 2 (1996): 127- 152.

Silverman, Kaja. Male Subjectivity at the Margins (New York \& London: Routledge, 1992).

Smith, Paul. "Eastwood Bound," Constructing Masculinity ed. Maurice Berger, Brian Wallis and Simon Watson (New York \& London: Routledge, 1995), 77- 97.

Yates, Candida. Masculine Jealousy and Contemporary Cinema (New York: Palgrave Macmillan, 2007).

Yıldırım,Nermin. “Kimin 'nefes'i.” Radikal 2, 1 Kasım 2009, http://www.radikal.com.tr/Radikal.aspx?aType=RadikalEklerDetayV3\&ArticleID=962213\&CategoryID=42.

Yuval-Davis, Nira. Cinsiyet ve Millet, çev. Ayşin Bektaş (İstanbul: İletişim, 2003).

Yücel, Fırat vd. Yuvarlak Masa Tartışması: “Nefes Vatan Sağolsun,” Altyazı 90 (2009): 82- 90. 